\title{
Antipsychotic treatments for the elderly: efficacy and safety of aripiprazole
}

\author{
This article was published in the following Dove Press journal: \\ Neuropsychiatric Disease and Treatment \\ I March 2010 \\ Number of times this article has been viewed
}

\author{
Izchak Kohen' \\ Paula E Lester ${ }^{2}$ \\ Sum Lam $^{3}$ \\ 'Division of Geriatric Psychiatry, \\ Zucker-Hillside Hospital, Glen Oaks, \\ NY, USA; ${ }^{2}$ Division of Geriatric \\ Medicine, Winthrop University \\ Hospital, Mineola, NY, USA; ${ }^{3}$ Division \\ of Pharmacy and Geriatrics, St. John's \\ University College of Pharmacy and \\ Allied Health Professions, Queens, \\ NY, USA
}

\begin{abstract}
Delusions, hallucinations and other psychotic symptoms can accompany a number of conditions in late life. As such, elderly patients are commonly prescribed antipsychotic medications for the treatment of psychosis in both acute and chronic conditions. Those conditions include schizophrenia, bipolar disorder, depression and dementia. Elderly patients are at an increased risk of adverse events from antipsychotic medications because of age-related pharmacodynamic and pharmacokinetic changes as well as polypharmacy. Drug selection should be individualized to the patient's previous history of antipsychotic use, current medical conditions, potential drug interactions, and potential side effects of the antipsychotic. Specifically, metabolic side effects should be closely monitored in this population. This paper provides a review of aripiprazole, a newer second generation antipsychotic agent, for its use in a variety of psychiatric disorders in the elderly including schizophrenia, bipolar disorder, dementia, Parkinson's disease and depression. We will review the pharmacokinetics and pharmacodynamics of aripiprazole as well as dosing, diagnostic indications, efficacy studies, and tolerability including its metabolic profile. We will also detail patient focused perspectives including quality of life, patient satisfaction and adherence.
\end{abstract}

Keywords: aripiprazole, antipsychotics, elderly, adverse drug reaction

\section{Introduction}

Antipsychotic medications are commonly prescribed for older adults for the acute management of psychosis in brief psychotic disorders or in psychosis due to a general medical condition or from substance use. Chronic antipsychotic therapy is commonly used in patients with psychosis, schizophrenia, dementia related psychosis, bipolar disorder, and psychosis related to Parkinson's disease.

Elderly patients are at increased risk of adverse drug events because of age-related pharmacodynamic and pharmacokinetic changes. Additionally, as older adults are often prescribed multiple medications, they are at increased risk for drug-drug interactions. Common side effects in the elderly from antipsychotics include orthostatic hypotension, sedation, anticholingergic side effects, extrapyramidal symptoms (tremor and rigidity), and tardive dyskinesia (lip smacking).

This paper provides a review of aripiprazole, a newer atypical antipsychotic agent. We will review the indications and adverse drug reactions of this drug in the elderly. Specifically, we will review pharmacokinetics and pharmacodynamics of aripiprazole as well as dosing, diagnostic indications, efficacy studies, and tolerability. We will also detail patient focused perspectives including quality of life, patient satisfaction and adherence.
Correspondence: Izchak Kohen North Shore-LIJ Health System, Zucker Hillside Hospital, Division of Geriatric Psychiatry, Ambulatory Care Pavilion, Room 2106, 75-59 263rd Street, Glen Oaks, NY I I004, USA

Tel 7।8-470-7992

Fax 7|8-962-77|2

Email ikohen@nshs.edu 


\section{Psychosis in the elderly}

Delusions, hallucinations and other psychotic symptoms can accompany a number of conditions in late life. A recent Swedish investigation found that the prevalence of any psychotic symptom in a population sample of 85-year-old individuals without dementia was $10.1 \%{ }^{1}$ Some conditions that cause psychotic symptoms, such as delirium and substance-induced psychosis are acute and tend to resolve when the underlying condition is treated. ${ }^{2}$ Psychotic symptoms in elderly individuals may also arise secondarily to Alzheimer's disease (AD) or other dementias. $\mathrm{AD}$ is the most common form of dementia in the elderly population, accounting for $65 \%$ to $70 \%$ of dementia cases. Approximately $35 \%$ to $50 \%$ of $\mathrm{AD}$ patients manifest psychotic symptoms. ${ }^{3}$ Psychosis associated with AD often presents with paranoid and nonbizarre delusions. ${ }^{4}$ Misidentification of care givers is common in patients with $\mathrm{AD}$, while schneiderian first rank symptoms are rare. ${ }^{5}$

\section{Schizophrenia in the elderly}

Schizophrenia, a chronic, mental illness affects about $1 \%$ of the US population and is characterized by both positive and negative symptoms, cognitive dysfunction and a decline in psychosocial functioning. ${ }^{6}$ The etiology of schizophrenia is unknown, but it is believed that monoamine neurotransmitter systems, particularly dopaminergic neurons, are involved. ${ }^{7}$ Most individuals with schizophrenia develop the disease in the second or third decade of life. Many patients with schizophrenia now live into older adulthood. Thus, about $80 \%$ of older adults with schizophrenia have had an early onset of the disease and have a chronic course spanning several decades. ${ }^{8}$ There is another smaller subset of patients who develop psychotic symptoms after age 60 and are diagnosed with very late onset schizophrenia-like psychosis. ${ }^{9}$ Factors distinguishing patients with very late onset schizophrenia from early onset schizophrenia patients include a lower genetic load, less evidence of a thought disorder, and evidence of a neurodegenerative component. ${ }^{10}$ The prevalence of schizophrenia among individuals aged 45 to 64 is approximately $0.6 \%$ and prevalence estimates for elderly individuals range from $0.1 \%$ to $0.5 \% .^{11,12}$

Longitudinal follow-up of patients with schizophrenia indicates a wide range of outcomes. About $20 \%$ of patients experience remission of all symptoms. ${ }^{13}$ Another 20\% experience worsening of their symptoms and the remaining $60 \%$ remain largely unchanged. ${ }^{14}$ Factors associated with poorer prognosis include chronicity, insidious onset, premorbid functional deficits, and prominent negative symptoms. ${ }^{15}$ In one large sample of chronically institutionalized patients with schizophrenia, older age was associated with lower levels of positive symptoms and higher levels of negative symptoms. ${ }^{16}$ Cognitive performance tends to be stable, although it is worse in patients with schizophrenia than in healthy adults. ${ }^{17}$ The degree of functional impairment varies among older adults with schizophrenia. However, one study showed that $30 \%$ of a group of older schizophrenic patients was employed at least part-time since the onset of psychosis and that $73 \%$ of them were living independently. ${ }^{18}$

\section{Psychosis in Alzheimer's dementia in the elderly}

Alzheimer's disease (AD) affects 5\% to $15 \%$ of the population over age 65 and about $20 \%$ of individuals over age $80 .{ }^{19}$ There is a high prevalence of psychotic symptoms and behavioral disturbance in AD. A review of studies showed a median prevalence rate of psychosis in $\mathrm{AD}$ of $41.1 \%$ (range, $12.2 \%$ to $74.1 \%$ ). ${ }^{20,21}$ Psychotic symptoms have been linked to increased cognitive and functional decline and increased risk of institutionalization in patients with $\mathrm{AD} .^{22}$

Antipsychotic medications are disproportionately used among elderly persons and are prescribed for more than a quarter of Medicare beneficiaries in nursing homes. ${ }^{23}$ Such medications are often used for dementia, delirium, psychosis, agitation, and affective disorders. ${ }^{24}$ Even though there is no psychotropic medication that is approved by the US Food and Drug Administration (FDA) for the treatment of psychosis in $\mathrm{AD}$, a number of consensus statements prior to 2004 recommend the use of atypical antipsychotic agents as a first line pharmacologic approach to treatment. ${ }^{25}$

Analyses of safety data from several studies have raised concerns about an increased risk of cerebrovascular adverse events such as stroke in the use of certain atypical antipsychotics compared with placebo in elderly patients with dementia. ${ }^{26,27}$ This has led the FDA to issue warnings on the use of atypical antipsychotics in the treatment of behavioral symptoms in elderly patients with dementia. ${ }^{19}$ In a Public Health Advisory issued in April 2005, the FDA warned that the use of atypical antipsychotic medications nearly doubled the risk of death, as compared with the risk with placebo, in 17 short-term, randomized, controlled trials involving elderly persons with dementia. ${ }^{28}$ The FDA has issued a separate warning regarding the increased mortality risk in elderly patients with dementia who are treated with atypical antipsychotics including aripiprazole. ${ }^{29}$ 


\section{Bipolar disorder in the elderly}

Bipolar disorder in older adult populations has gained increasing attention due to the growing proportion of elderly in the United States and worldwide. ${ }^{30}$ One study reported the prevalence of bipolar disorder at $0.5 \%$ among individuals age 65 and older as bipolar illness persists into later life. ${ }^{31}$ A continuing unmet need is the identification of agents that are generally well tolerated and effective in later-life bipolar disorder. Medications that are first-line treatments in younger patients, such as lithium, may be poorly tolerated in older patients due to side effects and renal dysfunction. Additional strategies for bipolar disorder in late-life are needed. There are few evidence-based studies on which to base treatment decisions in geriatric patients with bipolar disorder. ${ }^{32}$

\section{Psychosis in Parkinson's disease}

Psychosis affects at least 5\% to $8 \%$ of medication-treated patients with idiopathic Parkinson's disease (PD). ${ }^{33}$ Treatment options include reducing medications used for the treatment of PD-related motor symptoms or introducing an atypical antipsychotic drug. Only clozapine has been demonstrated to be efficacious and tolerated in double-blind controlled trials. ${ }^{34}$

\section{Major depressive disorder in the elderly}

Major depressive disorder (MDD) is common in older adults, with estimates of prevalence of $6 \%$ to $10 \%$ in primary care population. ${ }^{35}$ Approximately $50 \%$ of older patient with
MDD do not respond completely to initial treatment with antidepressant pharmacotherapy. ${ }^{36}$ Recently, the use of atypical antipsychotic agents has been studied as adjunctive or augmentation pharmacotherapy for incomplete response in young to middle-aged adults with major depression. ${ }^{37}$ The addition of aripiprazole to standard antidepressant pharamacotherapy has been examined in young and mid-life patients with MDD..$^{38}$

\section{Pharmacology and pharmacokinetics/dynamics of aripiprazole}

Aripiprazole is a second-generation (atypical) antipsychotic that is approved for schizophrenia, manic or mixed episodes associated with biploar I disorder, and as an adjunctive treatment of major depressive disorder. It exhibits high affinity for D2, D3, 2-HT1a and 5-HT2a receptors, moderate affinity for D4, 5-HT2c, 5-HT7, alpha 1 adrenergic and H1 receptors, and no affinity for muscarinic receptors. It has moderate affinity for the serotonin reuptake transporter. ${ }^{39}$ The proposed mechanism of action for its efficacy is a combination of partial agonistic activity at D2 and 5-HT1A receptors and antagonistic activity at 5-HT2A receptors. ${ }^{40} \mathrm{It}$ is available in several dosage forms: intramuscular injection solution, oral solution, tablets, and orally disintegrating tablets. ${ }^{41}$

Table 1 compares the pharmacokinetic parameters of second-generation antipsychotics. Aripripazole has an active

Table I Pharmacokinetic parameters of selected antipsychotics ${ }^{101}$

\begin{tabular}{|c|c|c|c|c|c|}
\hline Drug & Bioavailability (\%) & Half-life (h) & $\begin{array}{l}\text { Major metabolic } \\
\text { pathway }\end{array}$ & $\begin{array}{l}\text { Active } \\
\text { metabolites }\end{array}$ & $\begin{array}{l}\text { Dosage } \\
\text { forms }\end{array}$ \\
\hline Aripiprazole & 87 & $\begin{array}{l}48-68 \\
\text { Dehydroaripiprazole: } \\
75-46\end{array}$ & $\begin{array}{l}\text { CYP3A4, } \\
\text { CYP2D6 }\end{array}$ & $Y$ & $\mathrm{~T}, \mathrm{O}, \mathrm{L}$ \\
\hline Clozapine & $|2-8|$ & $11-105$ & $\begin{array}{l}\text { CYPIA2, } \\
\text { CYP3A4, } \\
\text { CYP2CI9 }\end{array}$ & $Y$ & $\mathrm{~T}, \mathrm{O}$ \\
\hline Olanzapine & 80 & $20-70$ & $\begin{array}{l}\text { CYPIA2, } \\
\text { CYP3A4, } \\
\text { FMO3 }\end{array}$ & Y & $\mathrm{T}, \mathrm{I}, \mathrm{O}$ \\
\hline Paliperidone ER & 28 & 23 & $\begin{array}{l}\text { Renal unchanged } \\
(59 \%) \\
\text { Multiple pathway }\end{array}$ & $\mathrm{N}$ & ER \\
\hline Quetiapine & $5-13$ & 7 & CYP3A4 & $Y$ & $\mathrm{~T}$ \\
\hline Risperidone & 68 & $3-24$ & CYP2D6 & $Y$ & $\mathrm{~T}, \mathrm{O}, \mathrm{L}$ \\
\hline Risperidone Consta $^{\circledR}$ & & $3-6$ days & CYP2D6 & $Y$ & LAI \\
\hline Ziprasidone & 59 & $4-10$ & $\begin{array}{l}\text { Aldehyde oxidase, } \\
\text { CYP3A4 }\end{array}$ & $\mathrm{N}$ & C,I \\
\hline
\end{tabular}

Abbreviations: C, capsules; ER, extended release; I, injection; L, liquid solution, elixir or suspension; LAI, long-acting injectable; O, orally disintegrating tablets; T, tablet. 
metabolite (dehydroaripiprazole) that has affinities for D2 receptors and an elimination half-life of 94 hours. The drug reaches the peak plasma concentration $\left(\mathrm{T}_{\max }\right)$ between 3 to 5 hours, and achieves a steady-state concentration within 14 days. It can be taken with or without food, but high-fat meal delays $T_{\max }$ by 3 hours. Aripiprazole has a high volume of distribution $(4.9 \mathrm{~L} / \mathrm{kg})$ and is highly bound to albumin (>99\%). Due to its long half-life, high volume of distribution and high protein binding, the elderly patients may experience drug accumulation and drug interactions. It is particularly true in patients who have low albumin levels, which may end up with higher free aripriprazole drug concentration. Excessive drug effect in this population may justify dose reduction or extended dosing interval. In addition, aripriprazole is metabolized primarily by dehydrogenation and hydroxylation (CYP3A4 and CYP2D6), as well as N-dealkylation (CYP3A4). Due to CYP450 enzyme polymorphism, its elimination half-life may be prolonged to up to 150 hours in poor metabolizers which represents approximately $8 \%$ of Caucasians. Approximately $25 \%$ of the drug is excreted in the urine $(<1 \%$ as unchanged drug) and $55 \%$ in the feces (18\% as unchanged drug). Intramuscular doses have a bioavailability of $100 \%$, and a $\mathrm{T}_{\max }$ of 1 to 3 hours. Compared to oral doses, intramuscular doses achieve a 19\% higher peak plasma concentration, as well as a $90 \%$ higher drug exposure within 2 hours of dosing. ${ }^{41,42}$

Aripiprazole interacts with drugs that are inducers or inhibitors of CYP3A4 and CYP2D6 enzymes. ${ }^{43}$ The dose should be doubled when coadministered with CYP3A4 inducers, such as carbamazepine. The dose should be reduced to half of the usual dose if coadministered with CYP3A4 inhibitors (ketoconazole) or CYP 2D6 inhibitors (fluoxetine, paroxetine). ${ }^{44}$ Appropriate measures should be done when the interacting drugs are discontinued. No dosage adjustment is required in patients with renal or hepatic impairment. ${ }^{45}$ Intramuscular injections should be administered slowly into deep muscle mass. Oral doses may be administered with or without food. Tablet and oral solution may be interchanged on a mg-per-mg basis, up to $25 \mathrm{mg}$. Doses using $30 \mathrm{mg}$ tablets should be exchanged for $25 \mathrm{mg}$ oral solution. ${ }^{41}$ Orally disintegrating tablets are bioequivalent to the immediate release tablets, and should be placed in mouth immediately upon removal from foil blister. They dissolve rapidly in saliva and may be swallowed without liquid.

Table 2 shows the relative side effect incidence of selected antipsychotics in all age groups. However, use of antipsychotics in the elderly is linked with many unique concerns. Firstly, anticholinergic effects can be detrimental to those who may already have urinary symptoms, cognitive impairment, dry mouth, blurred vision and cardiac abnormalities. Secondly, orthostatic hypotension and sedation may contribute to falls in patients who have trouble with balance and gait. Thirdly, extrapyramidal symptoms can be associated with long term antipsychotic therapy. Patients with the comorbidity of PD are especially at risk for tremor and muscle rigidity. Aripriprazole has lower incidence of these troublesome adverse effects when compared to other available antipsychotics. A retrospective study evaluated the use of aripriprazole for schizophrenia/schizoaffective disorder, bipolar disorder and major depressive disorder in elderly patients. The study suggested that agitation/activation is the most commonly reported side effect. ${ }^{46}$

\section{Aripiprazole efficacy studies \\ Schizophrenia}

The recommended dosage for schizophrenia is 10 to $15 \mathrm{mg}$ once daily, titrate no more frequently than every 2 weeks, to maximum of $30 \mathrm{mg}$ daily. Aripiprazole demonstrated its efficacy in four short-term placebo controlled trials that enrolled acutely relapsed inpatients with schizophrenia. Three of these studies also included an active control group treated with either risperidone (one trial) or haloperidol (two trials).

Table 2 Relative side effect incidence of selected antipsychotics in the general population ${ }^{101}$

\begin{tabular}{|c|c|c|c|c|c|c|}
\hline Drug & Sedation & EPS & Anticholinergic & Orthostasis & Weight gain & Hyperprolactinemia \\
\hline Aripiprazole & + & + & + & + & + & + \\
\hline Clozapine & ++++ & + & ++++ & ++++ & ++++ & + \\
\hline Haloperidol & + & ++++ & + & + & + & +++ \\
\hline Olanzapine & ++ & ++ & ++ & ++ & ++++ & + \\
\hline Quetiapine & ++ & + & + & ++ & ++ & + \\
\hline Risperidone & + & ++ & + & ++ & ++ & ++r+ \\
\hline Ziprasidone & ++ & ++ & + & + & + & + \\
\hline
\end{tabular}

Notes: $+=$ low degree of symptoms, $++=$ medium degree of symptoms, $++++=$ high degree of symptoms. 
The primary measures were the Positive and Negative Syndrome Scale (PANSS ${ }^{47}$ and the Clinical Global Impression $(\mathrm{CGI})^{48}$ assessment. PANSS measures positive symptoms (delusions, conceptual disorganization, hallucinatory behavior, excitement, grandiosity, suspiciousness/persecution, and hostility) and negative symptoms (blunted affect, emotional withdrawal, poor rapport, passive apathetic withdrawal, difficulty in abstract thinking, lack of spontaneity/flow of conversation, stereotyped thinking). The CGI assessment reflects the impression of a skilled observer about the overall clinical state of the patient. ${ }^{48}$

Overall, aripiprazole (10 to $30 \mathrm{mg}$ daily) is more efficacious than placebo in all measure outcomes after 4 to 6 week of therapy. ${ }^{49-51}$ In a 6-week trial $(n=367)$, aripriprazole $10 \mathrm{mg}$ daily is superior to placebo in PANSS total score, but the lower dose groups did not demonstrate superiority to placebo. ${ }^{52}$ In another 4 -week placebo controlled trial ( $n=103$ ) comparing the dose range of $5 \mathrm{mg}$ daily to $30 \mathrm{mg}$ daily. Aripiprazole demonstrated efficacy only in a responder analysis based on the CGI-severity score. Overall, higher dose of aripiprazole offered no advantage over the lowest doses. A longer-term trial $(n=310)$ that enrolled patients who were symptomatically stable on other antipsychotic medications for at least 3 months. These patients were discontinued from their antipsychotic medications and randomized to aripiprazole $15 \mathrm{mg}$ daily or placebo for up to 26 weeks of observation for relapse. Patients receiving aripiprazole experienced a significantly longer time to relapse, defined as CGI Improvement score of $\geq 5$ (minimally worse), scores $\geq 5$ (moderately severe) on the hostility or uncooperativeness items of the PANSS, or $\geq 20 \%$ increase in the PANSS total score. ${ }^{53}$ These clinical trials did not include sufficient numbers of subjects aged 65 and over to determine whether they respond differently from younger patients.

Clinical trials of aripiprazole included few elderly patients and more data are needed on the effects of aripiprazole in this population, especially those with comorbid medical illnesses. ${ }^{54}$ In one study, aripiprazole was used to treat 10 elderly hospitalized patients between 62 and 85 years of age who manifested signs of psychosis related to schizophrenia or schizoaffective disorder. All patients had been treated previously with atypical and classic antipsychotics. Response was assessed by clinical observation of patients' behavior and Clinical Global Impression Scale assigned retrospectively. Seven patients responded to treatment, two did not respond, and one had a partial response. The mean Clinical Global Impression Scale scores improved from 6 (severely ill) at baseline to 2.3 (much improved) at discharge. Treatment was discontinued in the two patients who did not respond. Of the 7 patients who responded, 4 presented with positive symptoms and showed significant improvement while 3 presented with positive and negative symptoms and both symptoms improved significantly. Four patients had preexisting EPS and these symptoms decreased in three patients. In addition, two patients were able to discontinue antiparkinson medications. The reduction of both positive and negative symptoms of schizophrenia and the lack of significant EPS, tardive dyskinesia, sedation, weight gain, anticholinergic effects, and QTc prolongation gives preliminary indication that aripiprazole may be a safe and effective medication for elderly patients with schizophrenia or schizoaffective disorder. ${ }^{55}$

\section{Psychosis in Alzheimer's dementia in the elderly}

There have been three 10-week, placebo-controlled studies that have evaluated the efficacy and tolerability of aripiprazole for the treatment of psychosis related to AD. ${ }^{19} \mathrm{In}$ the De Deyn et al study, there were 208 outpatients who were given flexible dosing of aripiprazole (doses of 2 to $15 \mathrm{mg} /$ day). There was no statistical difference between aripiprazole and placebo in the primary outcome measure of the caregiver-assessment NPI psychosis subscale. However, the aripiprazole-treated patients showed significantly greater improvement on the Brief Psychiatric Rating Scale (BPRS) Psychosis and BPRS Core subscale scores at end point when compared to placebo. There was no statistical significant difference in the BPRS total score. ${ }^{56}$

In the Streim et al study, there were 256 inpatients with AD-related psychosis who were given flexible dosing of aripiprazole (doses of 2 to $15 \mathrm{mg}$ /day) with a mean aripiprazole dose at end point of $8.6 \mathrm{mg} /$ day. There was also no statistical difference between aripiprazole and placebo in the primary outcome measure of the caregiver-assessment NPI psychosis subscale. There were decreases in the Clinical Global Impression-Severity of Illness (CGI-S), but those were only clinically significant in week 8 . There was also statistically significant improvement in the Cohen-Mansfield Agitation Inventory (CMAI). ${ }^{57}$

In the Mintzer et al study, 487 institutionalized nursing home patients were randomized to fixed doses of either $2 \mathrm{mg} /$ day, $5 \mathrm{mg} /$ day, or $10 \mathrm{mg} /$ day. On the $10 \mathrm{mg} / \mathrm{d}$ dose, there was a statistically significant difference between aripiprazole and placebo on the Neuropsychiatric Inventory-Nursing Home (NPI-NH) Psychosis subscale score at week $10 .{ }^{58} \mathrm{It}$ is important to note that the incidence of EPS-related AEs in these 
studies was low across all treatment groups. ${ }^{19}$ There was no significant difference between placebo and aripiprazole in all the three studies for weight change. ${ }^{19}$

\section{Psychosis in Parkinson's disease}

One study evaluated the effect of aripiprazole on psychosis in PD in an open-label pilot study. Fourteen patients meeting entry criteria were started on aripiprazole $1 \mathrm{mg} /$ day and titrated up to a maximum dose of $5 \mathrm{mg}$ as needed. Subjects were evaluated on the Unified Parkinson's Disease Rating Scale (UPDRS) part III for motor function, the Neuropsychiatric Inventory (NPI), and the Brief Psychiatric Rating Scale (BPRS) for psychiatric response. Statistically significant improvement in mean BPRS and positive BPRS subscales occurred with open-label aripiprazole, but 8 subjects discontinued the study due to worsened Parkinsonism (3), worsened psychosis (2), worsening of both (2), and lack of efficacy (1). While some patients had a favorable response, aripiprazole was associated with an exacerbation of motor symptoms. In that small study on psychosis in $\mathrm{PD}$, aripiprazole did not appear promising. ${ }^{59}$

\section{Bipolar disorder}

Aripiprazole is approved by the FDA for the treatment of bipolar mania and for the long-term treatment of bipolar disorder. To stabilize the acute manic or mixed episodes, aripiprazole should be initiated at $15 \mathrm{mg}$ once daily as monotherapy or adjunctive to lithium or valproic acid; may increase to $30 \mathrm{mg}$ once daily if clinically indicated. The effective stabilization dose should be continued for up to 6 weeks. Aripiprazole demonstrated its efficacy in four 3-week, placebo-controlled trials in hospitalized patients with bipolar I disorder with manic or mixed episodes. These studies included patients with or without psychotic features, and 2 studies also included patients with or without a rapidcycling course. The primary instrument used for assessing manic symptoms was the Young Mania Rating Scale (Y-MRS), an 11-item clinician-rated scale that assesses the degree of manic symptomatology (irritability, disruptive/ aggressive behavior, sleep, elevated mood, speech, increased activity, sexual interest, language/thought disorder, thought content, appearance, and insight). The secondary instrument included the Clinical Global Impression - Bipolar (CGI-BP) Scale. ${ }^{60-62}$

As a maintenance therapy, aripiprazole is superior to placebo on time to the number of combined affective relapses (manic plus depressive), but it is unclear if it delays the time to occurrence of depression in these patients. In addition, these clinical trials did not include sufficient numbers of subjects aged 65 and over to determine whether they respond differently from younger patients.

One study looking at the use of aripiprazole in elderly patients is an open-label, prospective trial of aripiprazole therapy in 20 older adult patients with bipolar disorder. ${ }^{30}$ Older adults with bipolar I disorder (confirmed by the MiniInternational Neuropsychiatric Interview) who were currently suboptimally responsive to their prescribed medication treatments received 12 weeks of open-label aripiprazole added on to existing mood stabilizer medication treatment. Aripiprazole was initiated at $5 \mathrm{mg}$ daily and increased as tolerated. Efficacy outcomes included psychopathology measures (the Young Mania Rating Scale [YMRS] ${ }^{63}$ and the Hamilton Rating Scale for Depression [HAM-D]), ${ }^{64}$ extrapyramidal symptoms, and a level of functioning measure (the Global Assessment Scale $[\mathrm{GAS}]$ ). Twenty older adults (mean age $=59.6$ years, range 50 to 83 years) received aripiprazole therapy. Compared to baseline, individuals had significant reductions in mean depression scores (HAM-D baseline $=13.8$, HAM-D end point $=6.1, P<0.001$ ), as well as mania scores (YMRS baseline $=8.6$, YMRS end point $=3.9, P<0.03$ ). There were also significant improvements in functional status as measured by the GAS $(P<0.001)$. The mean $\pm \mathrm{SD}$ daily dose of aripiprazole was $10.26 \pm 4.9 \mathrm{mg} /$ day. Overall, aripiprazole was adequately tolerated in this older adult population. Aripiprazole therapy may reduce symptoms in bipolar older adults, and it appears to be reasonably tolerated. However, larger, controlled trials are needed to confirm these preliminary findings. ${ }^{30}$

\section{Agitation associated with schizophrenia or bipolar mania}

The recommended dosage is $9.75 \mathrm{mg}$ (range 5.25 to $15 \mathrm{mg}$ ) as a single intramuscular dose, repeat at no more frequently than every 2 hours to a maximum of $30 \mathrm{mg}$ daily; transit to oral therapy as soon as possible if ongoing therapy is indicated. The efficacy of aripiprazole for the treatment of agitation was established in 3 short-term (24-hour), placebocontrolled trials in agitated inpatients with schizophrenia or bipolar I disorder (manic or mixed episodes, with or without psychotic features). Each trial included an active controlled arm of either haloperidol injection (schizophrenia studies) or lorazepam injection (bipolar Mania study). The efficacy measures were the change from baseline in the PANSS Excited Component at 2 hours post-injection and the Clinical Global Impression of Improvement (CGI-I) Scale. ${ }^{65,66}$ Again, these studies did not include sufficient numbers of subjects aged 
65 and over to determine whether they respond differently from younger patients.

\section{Major depressive disorder}

The use of aripiprazole for MDD in older patients has been looked at only in a limited fashion. One open trial of aripiprazole augmentation in 20 older adults with MDD that had not remitted after 6 weeks of treatment with a selective serotonin reuptake inhibitor (SSRI) was associated with improvement in $50 \%$ of the patients. ${ }^{67}$ Another 12-week, open-label pilot study of 24 patients diagnosed with MDD who responded partially (17-item Hamilton Rating Scale for Depression [HAM-D-17] score of 11 to 15) or not at all (HAM-D score $>15$ ) to a 16-week trial of escitalopram (up to $20 \mathrm{mg} /$ day), followed by either duloxetine (up to $120 \mathrm{mg}$ /day) or venlafaxine (up to $225 \mathrm{mg}$ /day) for 12 weeks. Subjects received 2.5 to $15 \mathrm{mg}$ per day of adjunctive aripiprazole (mean dose, $9.0 \mathrm{mg} /$ day) for 12 weeks. The criterion for remission during treatment with aripiprazole was a HAM-D score $\leq 10$ for 2 consecutive weeks. Of 24 subjects in the intent-to-treat study group, 19 completed 12 weeks of augmentation with aripiprazole, 12 of 24 (50\%) met criteria for remission, and 2 of 24 discontinued due to side effects (sedation, akathisia). The mean (SD) HAM-D score decreased significantly by 6.4 (5.8) points (paired t test for means, $P<0.01$, df $=16$ ). There were no relapses among the 12 subjects who participated in continuation treatment over a median period of 27.6 weeks. ${ }^{68}$ No known randomized controlled trials have looked at this phenomenon.

\section{Aripiprazole: safety and tolerability}

Second-generation antipsychotics (SGAs) are used to treat psychiatric conditions in elderly patients, including schizophrenia, mood disorders, and dementia with agitation and delusions. ${ }^{25}$ Aripiprazole is a SGA with partial agonist activity at the D2, D3, and 5HT1A receptors and antagonist activity at the 5-HT2A receptors. ${ }^{39}$

\section{Data from Phase II and III trials}

In Phase II and III trials, aripiprazole exhibited a favorable safety and tolerability profile. It showed a low propensity to cause significant adverse effects, such as extrapyramidal side effects (EPS), weight gain, cardiovascular abnormalities, hyperprolactinemia, hypercholesterolemia, or glucose dysregulation. ${ }^{49,69-70}$ In a meta-analysis assessing safety and tolerability data from the Phase II and Phase III trials, 1539 patients receiving aripiprazole $(n=926)$, haloperidol $(n=200)$, or placebo $(n=413)$ were assessed. The reported incidence of common adverse effects with aripiprazole was comparable to that of placebo. ${ }^{71}$ The most common side effects reported with aripiprazole $(>10 \%$ incidence) were headache, insomnia, agitation, and anxiety. Other common side effects were dyspepsia, nausea and vomiting, lightneadedness, somnolence, constipation and akathisia. Discontinuation due to adverse events occurred at an incidence rate of $7 \%$ with aripiprazole compared to $8 \%$ with haloperidol and $10 \%$ with placebo..$^{71}$ The most frequent adverse events leading to discontinuation of aripiprazole included psychosis (3.6\%), agitation $(0.6 \%)$ and akathisia $(0.6 \%)$. The incidence rate of EPS-related adverse events had no significant difference in between the placebo and aripiprazole treatment groups. Tardive dyskinesia was only reported by 2 of the aripiprazole-treated patients $(0.2 \%) .{ }^{71}$ At endpoint, patients showed minimal mean increase in body weight from baseline $(<1 \mathrm{~kg})$ on aripiprazole. In all, $8.1 \%$ of patients on aripiprazole experienced clinically significant weight gain $(>7 \%$ increase from baseline).${ }^{71}$ Aripiprazole was associated with decreased in serum prolactin levels. There was no dose-response relationship between aripiprazole and changes in the QTc interval. ${ }^{71}$ The median increase in fasting total cholesterol from baseline observed with aripiprazole treatment was low and did not differ significantly from placebo. Only 5.5\% of patients on aripiprazole had abnormally elevated fasting glucose levels and only $1.4 \%$ of the patients on aripiprazole had random levels of glucose above $200 \mathrm{mg} / \mathrm{dL}$. ${ }^{71}$ There were no clinically important differences in the adverse event profile when stratified by age, gender or race in patients receiving aripiprazole. ${ }^{71}$

\section{Metabolic profile}

Metabolic syndrome is age dependent and more prevalent in older adults across cultures. ${ }^{72}$ Additional studies, have validated that aripiprazole has a favorable metabolic safety profile. ${ }^{40,73}$ One study of 31 patients with schizophrenia showed that there was a significant decrease in body weight, body mass index, and weight circumference after 3 months of treatment with aripiprazole. There was also a significant reduction in fasting glucose, fasting insulin, insulin resistance index and serum lipid levels. ${ }^{74}$ In addition, aripiprazole did not induce hyperprolactinemia at end point compared with baseline in a meta-analysis. ${ }^{60}$ In one trial, as compared to olanazpine, aripiprazole was associated with weight loss and lesser changes in total cholesterol. ${ }^{75}$

One retrospective chart review of 52 inpatient geriatric patients who received aripiprazole described side effects attributed to aripiprazole in the charts of $9(17.3 \%)$ 
of the patients. Of these 9 patients, 7 had not received aripiprazole until the current hospitalization. Side effects were reported in a higher percentage of male than female patients (25\% versus $15 \%)$; however, this did not reach statistical significance. The most commonly reported side effect was agitation/activation, which was documented in the charts of 4 patients (8\%). Extrapyramidal symptoms were reported in 2 patients, and single cases of confusion, fatigue, and lightheadedness were also reported. The mean dose at which side effects were reported was $11.4 \mathrm{mg} /$ day. Side effects were the reported reason for aripiprazole discontinuation in $12 \%$ or 6 of the patients. ${ }^{46}$

\section{Patient-focused perspectives Quality of life}

Quality of life is important for all individuals, especially for people with schizophrenia on chronic medications. However, quality of life can be difficult to define and quantify as it relies on individual perception and selfassessment. Definitions vary from "whatever the individual defines it to be" to those that emphasize fulfillment of personal goals. ${ }^{76}$ Quality of life in the geriatric population can be even harder to define as it may depend less on sexual dysfunction and more on functions of activities of daily living (eg, bathing, dressing, food preparation). Additionally, studies on quality of life and patient adherence with aripiprazole (the STAR study) have excluded patients over 65 years of age. ${ }^{77,78}$

Data on the impact of aripiprazole therapy on the quality of life of schizophrenic patients are scarce and characterized by conflicting results. ${ }^{79-81}$ The only double-blind study which compared changes in quality of life among patients on aripiprazole versus perphenazine treatment failed to demonstrate statistically significant differences between the groups ${ }^{81}$ A Cochrane systemic review revealed no conclusive evidence of a clinically important improvement in quality of life as assessed by the Quality of Life Scale among 154 patients receiving aripaprazole. ${ }^{82}$

Patients with schizophrenia often have cognitive deficits such as decreases in attention, executive function and motor skills which impede their quality of life. ${ }^{83}$ Typical antipsychotics can contribute to such cognitive impairments through parkinsonism motor impairment or anticholinergic side effects. As an atypical antipsychotic, aripiprazole has shown a modest improvement in cognitive function, however such studies are few in number. ${ }^{84}$ On open label study revealed no improvement in neurocognitive function in patients on aripiprazole as compared to olanzapine. ${ }^{85}$

\section{Patient satisfaction/acceptability}

Patients over age 65 are at greater risk of metabolic side effects of antipsychotics because of their age and presence of comorbidities. Data on aripiprazole's impact on metabolic measures specifically in the geriatric population are not available. Studies have suggested that aripiprazole has a lower risk for weight gain than other atypical antipsychotics. ${ }^{86}$ A randomized trial of 173 overweight patients of all ages with schizophrenia or schizoaffective disorder comparing aripiprazole with olanzapine found aripiprazole was associated with weight loss and less effect in total cholesterol at 16 weeks. ${ }^{75}$ Some findings suggest that older patients actually gain less weight than their younger counterparts from second-generation antipsychotics (SGA) ${ }^{87}$ Furthermore, patients with Alzheimer's disease receiving SGAs may exhibit less weight gain than younger patients without dementia. ${ }^{88}$

Regular physical activity is associated with reduced incidence of metabolic syndrome from SGA. This is true for older adults too. Park et al demonstrated that yearlong exercise of at least 20 minutes daily at 3 or more metabolic equivalents was associated with reduced incidence of metabolic risk factors. ${ }^{89}$ Reductions in body mass index were strongly associated with favorable changes in risk factors for metabolic syndrome. ${ }^{90}$ While all patients on SGA should be advised on exercise and diet to minimize the potential effects of the metabolic syndrome, older patients may have poor compliance due to physical or financial limitations. Difficulty obtaining healthier food choices because of cost or availability and inability to exercise due to physical functional restrictions can make it harder for geriatric patients to comply with lifestyle changes.

\section{Adherence}

Nonadherence with prescribed medication regimens can result in increased morbidity, mortality, and resource utilization. ${ }^{91,92}$ Schizophrenic patients with poor adherence with antipsychotic medications have greater symptom levels, ${ }^{93}$ sustained functional impairment, ${ }^{94}$ poor community adjustment, ${ }^{95}$ higher risk of relapse, ${ }^{96}$ and more rehospitalization and emergency room use. ${ }^{97,98}$ A 2007 meta-analysis of hospitalization costs associated with antipsychotic nonadherence in the treatment of schizophrenia measured the impact of nonadherence in terms of direct healthcare costs or inpatient days. The study found poor adherence to antipsychotic medications was consistently associated with higher hospitalization costs with a higher risk of relapse and rehospitalization. However, the studies this article reviewed 
did not include the newer atypical antipsychotics including aripirazole, ziprasidone or paliperidone. ${ }^{99}$

\section{Discussion}

A variety of psychiatric conditions in the elderly can be treated with antipsychotic medications. Poor adherence to typical antipsychotics due to adverse reactions led to the newer atypical antipsychotics. However, the metabolic side effects of the second generation antipsychotics led to the development of a newer atypical antipsychotic, aripiprazole.

Older patients often require complex decision-making for medication management of psychiatric illness because they frequently have co-morbidity with medical conditions and are prescribed many other medications. They are at greater risk of metabolic and other side effects of antipsychotics because of their age and presence of comorbidities.

In particular, since the FDA black box warning that use of atypical antipsychotic medications in elderly patients with dementia nearly doubled the risk of death, clinicians, patients and caregivers are left with unclear choices for treating people with dementia with psychosis and/or severe agitation. Such behaviors are common and can cause considerable caregiver stress. The alternatives for treatment include no treatment, use of other psychotropic drugs, and psychotherapeutic and psychosocial interventions. No treatment may only be viable in mild cases or if symptoms are not disturbing to the patient or impairing function. There are limited studies on use of antidepressants, cholinesterase inhibitors and memantine for dementia related psychosis which generally were of limited utility (details are beyond the scope of this paper). There are limited randomized-control trials on the role of psychosocial and behavioral treatments for this population; however an individualized approach to such treatments may be appropriate for some patients. ${ }^{100}$ Even though there is no psychotropic medication that is approved by the FDA for the treatment of psychosis in $\mathrm{AD}$, a number of consensus statements prior to 2004 recommend the use of atypical antipsychotic agents as a first-line pharmacologic approach to treatment. ${ }^{25}$ Careful discussion of risks, benefits and alternative treatments should be conducted by clinicians with patients' caregivers when using antipsychotic medications for patients with dementia-related psychosis. Higher symptom burden will likely contribute to greater acceptance of using antipsychotic in hopes of improving quality of life.

In addition to its use in dementia, aripiprazole may be effective for the treatment of a variety of psychiatric conditions in the elderly including psychosis due to schizophrenia, bipolar disoder, depression, and PD. Although the data on aripiprazole's efficacy in the treatment of psychosis in the geriatric population are very limited, it may have an important role to play in those conditions. As discussed in detail above, aripiprazole has a favorable metabolic profile compared to other second-generation agents in terms of glycemic control, lipid profiles, prolactin levels and weight gain. When appropriate, clinicians should weigh the limited evidence of efficacy in the geriatric population with the potential benefits of less metabolic complications as its metabolic risk profile makes aripiprazole an attractive agent in this population. Additional studies on efficacy of aripiprazole use in the elderly population are needed, although early studies show some promise.

\section{Disclosures}

The authors have no conflicts of interest to report.

\section{References}

1. Ostling S, Skoog I. Psychotic symptoms and paranoid ideation in a nondemented population-based sample of the very old. Arch Gen Psychiatry. 2002;59(1):53-59.

2. Jeste DV, JL W, CR D. Schizophrenia and paranoid disorders. In: Blazer DG SD, Busse EW editors. Textbook of Geriatric Psychiatry. 3rd ed. Washington, DC: Amerian Psychiatric Publishing, Inc; 2004 pp. 269-281.

3. Cummings JL, F. BD. Dementia: A clinical approach. 2nd ed. Boston: Butterworth-Heinemann; 1992.

4. Jeste DV, Finkel SI. Psychosis of Alzheimer's disease and related dementias. Diagnostic criteria for a distinct syndrome. Am J Geriatr Psychiatry. 2000;8(1):29-34.

5. Burns A, Jacoby R, Levy R. Psychiatric phenomena in Alzheimer's disease. IV: Disorders of behaviour. Br J Psychiatry. 1990;157: 86-94.

6. Freedman R. Schizophrenia. N Engl J Med. 2003;349(18):1738-1749.

7. Worrel JA, Marken PA, Beckman SE, Ruehter VL. Atypical antipsychotic agents: a critical review. Am J Health Syst Pharm. 2000;57(3): 238-255.

8. Castle DJ, Murray RM. The epidemiology of late-onset schizophrenia. Schizophr Bull. 1993;19(4):691-700.

9. Howard R, Rabins PV, Seeman MV, Jeste DV. Late-onset schizophrenia and very-late-onset schizophrenia-like psychosis: an international consensus. The International Late-Onset Schizophrenia Group. Am J Psychiatry. 2000;157(2):172-178.

10. Howard RJ, Graham C, Sham P, et al. A controlled family study of late-onset non-affective psychosis (late paraphrenia). Br J Psychiatry. 1997; 170:511-514.

11. Copeland JR, Dewey ME, Scott A, et al. Schizophrenia and delusional disorder in older age: community prevalence, incidence, comorbidity, and outcome. Schizophr Bull. 1998;24(1):153-161.

12. Keith SJ, Reiger DA, Rae DS. Schizophrenic disorders in America: the epidemiologic catchment area study. New York: Free Press; 1991.

13. Huber G. The heterogeneous course of schizophrenia. Schizophr Res. 1997;28(2-3):177-185.

14. Belitsky R, McGlashan TH. The manifestations of schizophrenia in late life: a dearth of data. Schizophr Bull. 1993;19(4):683-685.

15. Ram R, Bromet EJ, Eaton WW, Pato C, Schwartz JE. The natural course of schizophrenia: a review of first-admission studies. Schizophr Bull. 1992;18(2):185-207.

16. Davidson M, Harvey PD, Powchik P, et al. Severity of symptoms in chronically institutionalized geriatric schizophrenic patients. Am J Psychiatry. 1995;152(2):197-207. 
17. Heaton RK, Gladsjo JA, Palmer BW, Kuck J, Marcotte TD, Jeste DV. Stability and course of neuropsychological deficits in schizophrenia. Arch Gen Psychiatry. 2001;58(1):24-32.

18. Palmer BW, McClure FS, Jeste DV. Schizophrenia in late life: findings challenge traditional concepts. Harv Rev Psychiatry. 2001;9(2):51-58.

19. Madhusoodanan S, Shah P. Management of psychosis in patients with Alzheimer's disease: focus on aripiprazole. Clin Interv Aging. 2008;3(3):491-501.

20. Paulsen JS, Salmon DP, Thal LJ, et al. Incidence of and risk factors for hallucinations and delusions in patients with probable AD. Neurology. 2000;54(10):1965-1971.

21. Ropacki SA, Jeste DV. Epidemiology of and risk factors for psychosis of Alzheimer's disease: a review of 55 studies published from 1990 to 2003. Am J Psychiatry. 2005;162(11):2022-2030.

22. Lopez OL, Wisniewski SR, Becker JT, Boller F, DeKosky ST. Psychiatric medication and abnormal behavior as predictors of progression in probable Alzheimer disease. Arch Neurol. 1999;56(10):1266-1272.

23. Briesacher BA, Limcangco MR, Simoni-Wastila L, et al. The quality of antipsychotic drug prescribing in nursing homes. Arch Intern Med. 2005;165(11):1280-1285.

24. Dewa CS, Remington G, Herrmann N, Fearnley J, Goering P. How much are atypical antipsychotic agents being used, and do they reach the populations who need them? A Canadian experience. Clin Ther. 2002;24(9):1466-1476.

25. Alexopoulos GS, J S, Carpenter D, et al. The expert consensus guideline series: using antipsychotics in older patients. J Clin Psychiatry. 2004; 65(Suppl 2).

26. Wooltorton E. Risperidone (Risperdal): increased rate of cerebrovascular events in dementia trials. CMAJ. 2002;167(11):1269-1270.

27. Wooltorton E. Olanzapine (Zyprexa): increased incidence of cerebrovascular events in dementia trials. CMAJ. 2004;170(9):1395.

28. Administration. FaD. FDA public health advisory: deaths with antipsychotics in elderly patients with behavioral disturbances. http://www.fda.gov/cder/drug/advisory/antipsychotics.htm. Accessed November 3, 2005.

29. Madhusoodanan S, Shah P, Brenner R, Gupta S. Pharmacological treatment of the psychosis of Alzheimer's disease: what is the best approach? CNS Drugs. 2007;21(2):101-115.

30. Sajatovic M, Coconcea N, Ignacio RV, et al. Aripiprazole therapy in 20 older adults with bipolar disorder: a 12-week, open-label trial. J Clin Psychiatry. 2008;69(1):41-46.

31. Hirschfeld RM, Calabrese JR, Weissman MM, et al. Screening for bipolar disorder in the community. J Clin Psychiatry. 2003;64(1):53-59.

32. Gildengers AG, Mulsant BH, Begley AE, et al. A pilot study of standardized treatment in geriatric bipolar disorder. Am J Geriatr Psychiatry. 2005;13(4):319-323.

33. Friedman JH, Factor SA. Atypical antipsychotics in the treatment of drug-induced psychosis in Parkinson's disease. Mov Disord. 2000; 15(2):201-211.

34. Low-dose clozapine for the treatment of drug-induced psychosis in Parkinson's disease. The Parkinson Study Group. $N$ Engl J Med. 1999;340(10):757-763.

35. Bruce ML, Ten Have TR, Reynolds CF, 3rd, et al. Reducing suicidal ideation and depressive symptoms in depressed older primary care patients: a randomized controlled trial. JAMA. 2004;291(9):1081-1091.

36. Unutzer J, Katon W, Callahan CM, et al. Collaborative care management of late-life depression in the primary care setting: a randomized controlled trial. JAMA. 2002;288(22):2836-2845.

37. Papakostas GI, Shelton RC, Smith J, Fava M. Augmentation of antidepressants with atypical antipsychotic medications for treatmentresistant major depressive disorder: a meta-analysis. J Clin Psychiatry. 2007;68(6):826-831.

38. Berman RM, Marcus RN, Swanink R, et al. The efficacy and safety of aripiprazole as adjunctive therapy in major depressive disorder: a multicenter, randomized, double-blind, placebo-controlled study. J Clin Psychiatry. 2007;68(6):843-853.
39. Burris KD, Molski TF, Xu C, et al. Aripiprazole, a novel antipsychotic, is a high-affinity partial agonist at human dopamine D2 receptors. J Pharmacol Exp Ther. 2002;302(1):381-389.

40. DeLeon A, Patel NC, Crismon ML. Aripiprazole: a comprehensive review of its pharmacology, clinical efficacy, and tolerability. Clin Ther. 2004;26(5):649-666.

41. Ltd OPC. Product information: ABILIFY(R) oral tablets, oral solution, IM injection, ABILIFY DISCMELT(R) orally disintegrating tables, aripiprazole oral tablets, oral solution, IM injection, orally disintegrating tablets. Tokyo, Japan; 2009.

42. Boulton DW, Kollia G, Mallikaarjun S, et al. Pharmacokinetics and tolerability of intramuscular, oral and intravenous aripiprazole in healthy subjects and in patients with schizophrenia. Clin Pharmacokinet. 2008;47(7):475-485.

43. Waade RB, Christensen H, Rudberg I, Refsum H, Hermann M. Influence of comedication on serum concentrations of aripiprazole and dehydroaripiprazole. Ther Drug Monit. 2009;31(2):233-238.

44. Citrome L, Macher JP, Salazar DE, Mallikaarjun S, Boulton DW. Pharmacokinetics of aripiprazole and concomitant carbamazepine. J Clin Psychopharmacol. 2007;27(3):279-283.

45. Mallikaarjun S, Shoaf SE, Boulton DW, Bramer SL. Effects of hepatic or renal impairment on the pharmacokinetics of aripiprazole. Clin Pharmacokinet. 2008;47(8):533-542.

46. Coley KC, Scipio TM, Ruby C, Lenze EJ, Fabian TJ. Aripiprazole prescribing patterns and side effects in elderly psychiatric inpatients. $J$ Psychiatr Pract. 2009;15(2):150-153.

47. Kay SR, Fiszbein A, Opler LA. The positive and negative syndrome scale (PANSS) for schizophrenia. Schizophr Bull. 1987;13(2): 261-276.

48. Mortimer AM. Symptom rating scales and outcome in schizophrenia. Br J Psychiatry Suppl. 2007;50:s7-s14.

49. Kane JM, Carson WH, Saha AR, et al. Efficacy and safety of aripiprazole and haloperidol versus placebo in patients with schizophrenia and schizoaffective disorder. J Clin Psychiatry. 2002;63(9):763-771.

50. McEvoy JP, Daniel DG, Carson WH Jr, McQuade RD, Marcus RN. A randomized, double-blind, placebo-controlled, study of the efficacy and safety of aripiprazole 10,15 or $20 \mathrm{mg}$ /day for the treatment of patients with acute exacerbations of schizophrenia. J Psychiatr Res. 2007;41(11):895-905.

51. Potkin SG, Saha AR, Kujawa MJ, et al. Aripiprazole, an antipsychotic with a novel mechanism of action, and risperidone vs placebo in patients with schizophrenia and schizoaffective disorder. Arch Gen Psychiatry. 2003;60(7):681-690.

52. Cutler AJ, Marcus RN, Hardy SA, O'Donnell A, Carson WH, McQuade RD. The efficacy and safety of lower doses of aripiprazole for the treatment of patients with acute exacerbation of schizophrenia. CNS Spectr. 2006;11(9):691-702; quiz 719.

53. Pigott TA, Carson WH, Saha AR, Torbeyns AF, Stock EG, Ingenito GG. Aripiprazole for the prevention of relapse in stabilized patients with chronic schizophrenia: a placebo-controlled 26-week study. J Clin Psychiatry. 2003;64(9):1048-1056.

54. [package insert] Ap. Otsuka America Pharmaceutical, Inc., Rockville MD and Bristol-Myers Squibb Co., Princeton NJ; November 2002.

55. Madhusoodanan S, Brenner R, Gupta S, Reddy H, Bogunovic O. Clinical experience with aripiprazole treatment in ten elderly patients with schizophrenia or schizoaffective disorder: retrospective case studies. CNS Spectr. 2004;9(11):862-867.

56. De Deyn P, Jeste DV, Swanink R, et al. Aripiprazole for the treatment of psychosis in patients with Alzheimer's disease: a randomized, placebocontrolled study. J Clin Psychopharmacol. 2005;25(5):463-467.

57. Streim JE, Breder C, Swanink R, et al. Flexible dose aripiprazole in psychosis of Alzheimer's dementia (poster): Presented at the 157th American Psychiatric Association Meeting; 2004.

58. Mintzer JE, Tune LE, Breder CD, et al. Aripiprazole for the treatment of psychoses in institutionalized patients with Alzheimer dementia: a multicenter, randomized, double-blind, placebo-controlled assessment of three fixed doses. Am J Geriatr Psychiatry. 2007;15(11):918-931. 
59. Friedman JH, Berman RM, Goetz CG, et al. Open-label flexible-dose pilot study to evaluate the safety and tolerability of aripiprazole in patients with psychosis associated with Parkinson's disease. Mov Disord. 2006;21(12):2078-2081.

60. Keck PE Jr, Calabrese JR, McQuade RD, et al. A randomized, doubleblind, placebo-controlled 26-week trial of aripiprazole in recently manic patients with bipolar I disorder. J Clin Psychiatry. 2006;67(4): 626-637.

61. Keck PE Jr, Marcus R, Tourkodimitris S, et al. A placebo-controlled, double-blind study of the efficacy and safety of aripiprazole in patients with acute bipolar mania. Am J Psychiatry. 2003;160(9):1651-1658.

62. Sachs G, Sanchez R, Marcus R, et al. Aripiprazole in the treatment of acute manic or mixed episodes in patients with bipolar I disorder: a 3-week placebo-controlled study. J Psychopharmacol. 2006;20(4):536-546.

63. Young RC, Biggs JT, Ziegler VE, Meyer DA. A rating scale for mania: reliability, validity and sensitivity. Br J Psychiatry. 1978;133: 429-435.

64. Hamilton M. A rating scale for depression. J Neurol Neurosurg Psychiatry. 1960;23:56-62.

65. Andrezina R, Josiassen RC, Marcus RN, et al. Intramuscular aripiprazole for the treatment of acute agitation in patients with schizophrenia or schizoaffective disorder: a double-blind, placebo-controlled comparison with intramuscular haloperidol. Psychopharmacology (Berl) 2006;188(3):281-292.

66. Tran-Johnson TK, Sack DA, Marcus RN, Auby P, McQuade RD, Oren DA. Efficacy and safety of intramuscular aripiprazole in patients with acute agitation: a randomized, double-blind, placebo-controlled trial. $J$ Clin Psychiatry. 2007;68(1):111-119.

67. Rutherford B, Sneed J, Miyazaki M, et al. An open trial of aripiprazole augmentation for SSRI non-remitters with late-life depression. Int $J$ Geriatr Psychiatry. 2007;22(10):986-991.

68. Sheffrin M, Driscoll HC, Lenze EJ, et al. Pilot study of augmentation with aripiprazole for incomplete response in late-life depression: getting to remission. J Clin Psychiatry. 2009;70(2):208-213.

69. Petrie JL, Saha AR, McEvoy JP. Aripiprazole, a new atypical antipsychotic: Phase 2 clinical trial results. Eur Neuropsychopharmacol. 1997;7 (Suppl 2):S227.

70. Daniel DG, Saha AR, Ingenito G, et al. Aripiprazole: a novel antipsychotic: Overview of phase II study results. Int J Neuropsychopharmacol. 2000;3(Suppl 1):S157.

71. Marder SR, McQuade RD, Stock E, et al. Aripiprazole in the treatment of schizophrenia: safety and tolerability in short-term, placebo-controlled trials. Schizophr Res. 2003;61(2-3):123-136.

72. Hildrum B, Mykletun A, Hole T, Midthjell K, Dahl AA. Age-specific prevalence of the metabolic syndrome defined by the International Diabetes Federation and the National Cholesterol Education Program: the Norwegian HUNT 2 study. BMC Public Health. 2007;7:220.

73. McQuade RD, Stock E, Marcus R, et al. A comparison of weight change during treatment with olanzapine or aripiprazole: results from a randomized, double-blind study. J Clin Psychiatry. 2004;65 Suppl 18:47-56.

74. De Hert M, Hanssens L, van Winkel R, et al. A case series: evaluation of the metabolic safety of aripiprazole. Schizophr Bull. 2007;33(3): 823-830.

75. Newcomer JW, Campos JA, Marcus RN, et al. A multicenter, randomized, double-blind study of the effects of aripiprazole in overweight subjects with schizophrenia or schizoaffective disorder switched from olanzapine. J Clin Psychiatry. 2008;69(7):1046-1056.

76. Quality of life compendiu. Center for Quality of Life Research in Nursing Science Section for Nursing Science, Department of Public Health and Primary Health Care, University of Bergen. URL: http://www.uib. no/isf/people/doc/qol/httoc.htm. Accessed August 28, 2009.

77. Hanssens L, L'Italien G, Loze JY, Marcus RN, Pans M, Kerselaers W. The effect of antipsychotic medication on sexual function and serum prolactin levels in community-treated schizophrenic patients: results from the Schizophrenia Trial of Aripiprazole (STAR) study (NCT00237913). BMC Psychiatry. 2008;8:95.
78. Taylor D, Hanssens L, Loze JY, Pans M, L'Italien G, Marcus RN Preference of medicine and patient-reported quality of life in community-treated schizophrenic patients receiving aripiprazole vs standard of care: results from the STAR study. Eur Psychiatry. 2008; 23(5):336-343.

79. Kasper S, Lerman MN, McQuade RD, et al. Efficacy and safety of aripiprazole vs haloperidol for long-term maintenance treatment following acute relapse of schizophrenia. Int J Neuropsychopharmacol. 2003;6(4):325-337.

80. McGavin JK, Goa KL. Aripiprazole. CNS Drugs. 2002;16(11):779-786; discussion 787-778.

81. Casey DE, Carson WH, Saha AR, et al. Switching patients to aripiprazole from other antipsychotic agents: a multicenter randomized study. Psychopharmacology (Berl). 2003;166(4):391-399.

82. El-Sayeh HG, Morganti C. Aripiprazole for schizophrenia. Cochrane Database Syst Rev. 2006;(2):CD004578.

83. Kasper S, Resinger E. Cognitive effects and antipsychotic treatment. Psychoneuroendocrinology. 2003;28 Suppl 1:27-38.

84. Lublin H, Eberhard J, Levander S. Current therapy issues and unmet clinical needs in the treatment of schizophrenia: a review of the new generation antipsychotics. Int Clin Psychopharmacol. 2005;20(4): 183-198.

85. Kern RS, Green MF, Cornblatt BA, et al. The neurocognitive effects of aripiprazole: an open-label comparison with olanzapine. Psychopharmacology (Berl). 2006;187(3):312-320.

86. Casey DE. Metabolic issues and cardiovascular disease in patients with psychiatric disorders. Am J Med. 2005;118 Suppl 2:15S-22S.

87. Basson BR, Kinon BJ, Taylor CC, Szymanski KA, Gilmore JA, Tollefson GD. Factors influencing acute weight change in patients with schizophrenia treated with olanzapine, haloperidol, or risperidone. J Clin Psychiatry. 2001;62(4):231-238.

88. Street JS, Clark WS, Gannon KS, et al. Olanzapine treatment of psychotic and behavioral symptoms in patients with Alzheimer disease in nursing care facilities: a double-blind, randomized, placebo-controlled trial. The HGEU Study Group. Arch Gen Psychiatry. 2000;57(10): 968-976.

89. Park S, Park H, Togo F, et al. Year-long physical activity and metabolic syndrome in older Japanese adults: cross-sectional data from the Nakanojo Study. J Gerontol A Biol Sci Med Sci. 2008;63(10): 1119-1123.

90. Stewart KJ, Bacher AC, Turner K, et al. Exercise and risk factors associated with metabolic syndrome in older adults. Am J Prev Med. 2005 Jan;28(1):9-18.

91. Solomon DK, Portner TS, Bass GE, et al. Clinical and economic outcomes in the hypertension and COPD arms of a multicenter outcomes study. J Am Pharm Assoc (Wash). 1998;38(5):574-585.

92. Schoen MD, DiDomenico RJ, Connor SE, Dischler JE, Bauman JL. Impact of the cost of prescription drugs on clinical outcomes in indigent patients with heart disease. Pharmacotherapy. 2001;21(12): $1455-1463$

93. Magura S, Laudet AB, Mahmood D, Rosenblum A, Knight E. Adherence to medication regimens and participation in dual-focus self-help groups. Psychiatr Serv. 2002;53(3):310-316.

94. Kelly GR, Scott JE, Mamon J. Medication compliance and health education among outpatients with chronic mental disorders. Med Care. 1990;28(12):1181-1197.

95. Corriss DJ, Smith TE, Hull JW, Lim RW, Pratt SI, Romanelli S. Interactive risk factors for treatment adherence in a chronic psychotic disorders population. Psychiatry Res. 1999;89(3):269-274.

96. Weiden PJ, Olfson M. Cost of relapse in schizophrenia. Schizophr Bull. 1995;21(3):419-429.

97. Green JH. Frequent rehospitalization and noncompliance with treatment. Hosp Community Psychiatry. 1988;39(9):963-966.

98. Olfson M, Mechanic D, Hansell S, Boyer CA, Walkup J, Weiden PJ. Predicting medication noncompliance after hospital discharge among patients with schizophrenia. Psychiatr Serv. 2000;51(2): $216-222$. 
99. Sun SX, Liu GG, Christensen DB, Fu AZ. Review and analysis of hospitalization costs associated with antipsychotic nonadherence in the treatment of schizophrenia in the United States. Curr Med Res Opin. 2007;23(10):2305-2312.

100. Jeste DV, Blazer D, Casey D, et al. ACNP White Paper: update on use of antipsychotic drugs in elderly per sons with dementia. Neuropsychopharmacology. 2008;33(5):957-970.
101. Crismon ML, Argo TR, Buckley PF. Schizophrenia. In: DiPiro JT, Talbert RL, Yee GC, et al. editors. Pharmacotherapy: A Pathophysiologic Approach, 7th ed. New York, McGraw-Hill; 2008. pp. 1099-1123.

\section{Publish your work in this journal}

Neuropsychiatric Disease and Treatment is an international, peerreviewed journal of clinical therapeutics and pharmacology focusing on concise rapid reporting of clinical or pre-clinical studies on a range of neuropsychiatric and neurological disorders. This journal is indexed on PubMed Central, the 'PsycINFO' database and CAS, and is the official journal of The International Neuropsychiatric Association (INA). The manuscript management system is completely online and includes a very quick and fair peer-review system, which is all easy to use. Visit http://www.dovepress.com/testimonials.php to read real quotes from published authors.

Submit your manuscript here: http://www.dovepress.com/neuropsychiatric-disease-and-treatment-journal 